\title{
A Hundred Years of Debates on Sex Differences: Developing Research for Social Change
}

\author{
Gabrielle Poeschl ${ }^{1}$ \\ [1] Department of Psychology, University of Porto, Porto, Portugal.
}

Journal of Social and Political Psychology, 2021, Vol. 9(1), 221-235, https://doi.org/10.5964/jspp.6399

Received: 2017-08-26 • Accepted: 2021-02-10 • Published (VoR): 2021-06-07

Handling Editor: Sherianne Kramer, University of Amsterdam, Amsterdam, The Netherlands

Corresponding Author: Gabrielle Poeschl, Rua Alfredo Allen, 4200-135 Porto, Portugal. E-mail: gpoeschl@fpce.up.pt

\begin{abstract}
After women secured the right to vote some hundred years ago, the assertions about their innate inferiority gradually began to vanish, giving way to theories about the countless aspects which apparently differentiated them from men. In this paper, we follow the evolution of research on sex differences, starting with the work of the first female psychologists who questioned the theories that justified women's subordinate positions in society. We trace the main developments of the studies on sex differences, their relationship with social roles, gender stereotypes, and gender identity, and describe the strategies used to highlight the role of society rather than of biology in shaping men and women's personalities and behaviors. We describe the controversies this area of research gave rise to, the debates over its political implications, and the changes observed over time in women's social positions and within research perspectives. Finally, we discuss the mutually reinforcing effects of social organization and lay conceptions of gender and reflect on how the field of research on sex differences has contributed to building a fairer society.
\end{abstract}

\section{Keywords}

gender, sex differences, social roles, gender stereotypes, gender identity, social change

The question of knowing whether men and women are different, and if so, in what ways and to what extent, has led to numerous studies over the last 100 years. These studies were often conducted by researchers eager to explain the social order through the identification of sex differences or wanting to break down the hierarchy of the sexes by challenging the existence of these apparent differences.

This paper describes roughly 100 years of research on the differences between men and women, considered as belonging to two distinct and homogeneous social categories. It begins at a time when the separation between paid work and domestic work established by the Industrial Revolution had created different roles for middle-class men and women (Scott, 1995), leading to the development of theories that justified women's subordinate social positions. Among these theories, the science of craniometry claimed to have proved on an objective basis that women were less intelligent than men by measuring the volume of the skull (cf. Gould, 1981). It was also believed that men presented a high variability in intelligence (more men in homes for the mentally deficient and more men "of genius"), whereas all women were of low intelligence (see Shields, 1975).

In the early 20th century, while the first wave of feminism was struggling for political power, the first female psychologists undertook studies on sex differences. This paper starts with a description of these groundbreaking studies that challenged theories suggesting that women were inferior to men. It goes on to show female authors' efforts to counter the conclusions of studies that justified separate social roles for men and women, and to present theories that explained the impact of culture and contexts on sex differences. It reports the controversies which arose among authors 
about the validity and objectives of the research on sex differences, and the criticisms stressing that this research had neither adequately defined "sex" nor considered the heterogeneity of the categories of men and women. It concludes with some examples of present-day research showing how social norms and beliefs continue to sustain discrimination against women and discusses the impact of this domain of research on social change.

In line with the social constructionist framework, which holds that people construct their realities through the social interactions that take place at particular times and places (Berger \& Luckman, 1966; Charmaz, 2006), the paper reflects ways of thinking about the nature of men and women in societies of Western culture, since the research on sex differences has mainly been conducted in the United States. By using the terms "sex" and "gender" as they were employed in the research described, it also highlights the culturally determined meanings associated with these concepts.

\section{Time 1. Are Men and Women Different?}

At the beginning of the 20th century, women from countries of Western culture were fighting for legal rights, such as the rights to vote or to own property. They were generally excluded from pursuing graduate training, as marriage and career were considered incompatible. This explains why so few women contributed to the new discipline of Psychology: in 1906, among the 175 members of the American Psychological Association, there were only 22 women (Furumoto \& Scarborough, 1986).

Among these women, Helen Woolley (1910) studied the similarities and differences between men and women's mental traits for her $\mathrm{PhD}$ thesis, and reviewed the then current publications on sex differences. She came to the following conclusions: though women might have smaller brains than men, this did not mean that they were less intelligent; there were no differences in creativity nor in color preferences; results of word association tasks were inconsistent; women's handwriting was smaller than men's; women's memory was better than men's; men performed motor functions more rapidly; girls and boys differed in their play activities; and women's sexual impulse was less intense than men's. She noted that there were few differences between men and women and that most of the differences were of social origin.

Woolley (1910) also observed several inconsistencies. For example, women were said to be both dominated by emotions and patient and self-controlled; they were said to have an innate tendency to lie but also to be ethically superior to men. From her analysis, she concluded that "there is perhaps no field aspiring to be scientific where flagrant personal bias, logic martyred in the cause supporting prejudice .... have run riot to such an extent as here" (Woolley, 1910, p. 340). For Woolley (1910), the allegation that women would not benefit from higher education stemmed from the fear that they would reduce their reproductive activity if they developed their intellectual capacities.

Woolley (1914) later noted that the increase in research on sex differences made it impossible to take every study into account, and she reiterated that scientific evidence played "very little part in producing convictions" (p. 372). She also observed that only a few male authors, such as Thorndike (1914), regarded the variations between the sexes as smaller than the variations within each sex, and too small to be important. Indeed, most of them agreed with men's greater variability in intelligence and attributed to biology what they considered to be the main difference between men and women: "the fighting instinct of the male and the nursing instinct of the female" (Woolley, 1914, p. 373). Woolley (1914) concluded that so-called feminine behaviors were the product of a society that prepared middle-class American women to be married, to perform the domestic role and to be economically dependent on men.

Leta Hollingworth who, for her $\mathrm{PhD}$ thesis, studied the supposed mental incapacity of women during their menstruation also reviewed the discourses on sex differences, comparing the abundant "literature of opinion" to the limited "literature of fact" (Hollingworth, 1916a, p. 224). She analyzed four assumptions justifying the division of roles by sex. She found no evidence that: men were, on average, more intelligent than women; men presented a higher mental variability than women; there were characteristics (such as menstruation) that affected women's intellectual abilities; there were differences in innate affects or instincts justifying a "natural" division of labor. She concluded that the apparent differences between men and women stemmed from the expectations of society that women should get married, have children, and raise them. 
For Hollingworth (1916b), the theories about human nature represented a means of social control. She argued that the "maternal instinct," which was said to characterize women, and their so-called vocation to procreate and raise children, were used as a justification to limit their education to the acquisition of the necessary skills for domestic work. She noted that the existence of laws punishing contraception, abortion, child desertion and infanticide nonetheless proved that not all women possess a maternal instinct. Hollingworth (1916b) concluded that the roles attributed to women only aimed to prevent them from living a life of their own.

In the early 20th century, biologists were also attempting to explain (and control) sex determination (see Ha, 2011). Theories regarding metabolism, chromosomes or hormones were proposed as explanations for the sexual development of males, females, and intersex individuals. These theories defended a plastic notion of sex, suggesting that males and females vary in degree, not in kind, and that sex is reversible. In this sense, they provided arguments for feminist and homosexual movements. However, by attempting to specify what distinguishes men from women, for example, that men are active and women passive, these theories also supported the existence of sex-related traits and aptitudes and were also welcomed by those concerned by homosexuality or feminist attempts to change social roles (Ha, 2011).

To summarize, at the beginning of the 20th century, female authors began to question the research that had so far been carried out on sex differences and which was used to demonstrate women's supposed inferiority. They argued that the few differences between the sexes were a product of the roles assigned to (middle-class) men and women, called for the right of women to choose how to live their lives and, ultimately, for equal rights for all. The view that sex differences had a biological basis was however widely shared.

\section{Time 2. Sex Differences and the Assessment of Masculinity and Femininity}

Women progressively gained the right to vote and, by the 1920s, North American women had obtained suffrage, the right to the ownership of property and access to education. These steps towards men and women's equality led authors to search for an explanation for the subordination of women and, consequently, pay more attention to the differences between the sexes (Connell, 1993). Research on sex differences, which had not been rigorously planned until then, began to be systematically conducted (Lee, 1976).

In collaboration with his former student Miles, Terman undertook the task of constructing a test of "mental masculinity and femininity" (Terman \& Miles, 1936). For almost 20 years, the authors questioned hundreds of individuals about their sentiments, interests, attitudes and behaviors to identify the items which were most likely to differentiate the sexes and which, therefore, should be included in the test (cf. Lee, 1976).

The final version of the questionnaire (Terman \& Miles, 1936) comprised seven tasks (word association, information, interests, introversion, emotion and ethical attitudes, ink-blot association, and personality and opinions). To give an example, in the first type of task, respondents were asked to choose from among four words the one they best associated with a stimulus word, for example, which word, from among "gun," "explosion," "rouge," "face," went best with "powder." The first two words were coded as a masculine answer and the last two words as a feminine answer. An M-F score was computed by subtracting the number of feminine answers from the number of masculine answers, making it possible to place any individual along a single bipolar continuum ranging from extreme masculinity to extreme femininity.

The results led Terman and Miles (1936) to conclude that men and women differed in two ways: in the direction of their interests and in the direction of their emotions and impulses. More precisely, according to the test, males were more interested in exploits and adventures, outdoor occupations, machinery and tools, science, physical phenomena, inventions, manifested greater self-assertion and aggressiveness, and were rougher in their manners, language, and sentiments. In contrast, females were more interested in domestic affairs and aesthetic objects, indoor occupations, occupations which involved assisting the young, the helpless and the distressed, they were more compassionate, sympathetic, timid, and more emotional than men.

Terman and Miles (1936) did not discuss the respective influence of nature and nurture on the origin of the differences between men and women, although they acknowledged that some factors, including education, occupation or family context, influenced individuals' scores of masculinity and femininity. They were indeed confident that there 
is a masculine temperament opposed to a feminine temperament because they believed that the masculine-feminine contrast, with various patterns, had always existed. The test spread the idea that the existence of a measurable psychological dimension of masculinity-femininity was scientifically proven, and this paved the way for a whole set of tests measuring "mental" masculinity and femininity (for a review, see Constantinople, 1973).

On the assumption that the two sexes had distinct interests, a masculinity-femininity scale of vocational interests was designed by Strong (1936) to improve the efficacy of the training and professional guidance of boys and girls. The author analyzed 420 items related to occupations, amusement, activities, etc. and observed that 88 were more often chosen by boys and men and 114 were more often chosen by girls and women. For example, male respondents declared more interest in "repairing electrical wiring," "boxing," "poker," and being a politician or a car salesman, and female respondents declared more interest in "decorating a room with flowers," "looking at shop windows," and being a secretary, a social worker or a school teacher.

Thus, Strong's (1936) results supported Terman and Miles' (1936) conclusions that there are differences between men and women's interests. In fact, the correlation (of 0.69) between the responses of the two sexes indicated more similarities than differences in their interests, but the results were viewed as explaining the differences in men and women's professional choices (Lee, 1976). This interpretation led to the belief that male professional interests were unsuitable for women and female professional interests were unsuitable for men. According to Lee (1976), Strong (1955) was concerned about the misuse of the M-F scales and later commented that if we look for similarity, we find it and if we look for difference, we find it too.

In brief, the masculinity-femininity tests focused on the differences between white middle-class American men and women rather than on their similarities. They did not explore the possibility that other cultures or other social classes might introduce variations in the definitions of masculinity and femininity, and they led to a prescriptive definition of what a "normal man" and a "normal woman" should be like.

\section{Time 3. Masculinity, Femininity and Sex Roles}

In the 1940s, the concept of "social role," that is, the enacted and/or expected behavior of individuals who occupy a given social position (see Nielsen, 1990) gained importance, and the terms "sex role," "male role" and "female role" began to be widely used (Connell, 1993). Research revealed that the cleavage in sex roles was associated with the assumption that men and women were different kinds of people: men were viewed as stronger, bolder, more logical and reasonable, and women as more delicate physically, but stronger morally, purer, more refined, more understanding and sensitive (Seward, 1946; for a historical perspective on men and women's roles, see Nielsen, 1990). Moreover, according to Seward (1946), it was commonly assumed that the personalities of men and women were "intrinsic in the biology of sex" (pp. 142-143) and not molded by separate subcultures.

In the 1950s, Parsons (Parsons \& Bales, 1955) explicitly associated the supposed differences between men and women with the public and private spheres, applying to the family the theory proposed by Bales (1950) on the functioning of small groups. According to this theory, at the origin of each small group there is a need to carry out a task. The stability of the groups is ensured by the existence of two leaders: an instrumental leader, who focuses on the task, and a socio-emotional leader, who focuses on the group members. For Parsons and Bales (1955), the family was typically a small group, in which men performed the instrumental role of breadwinner, and women the expressive or socio-emotional role of caregiver. In their view, the family was efficiently held together by the complementarity of men and women's roles, since, just as in other types of small groups, a single member could not perform both the expressive and instrumental functions (see Michel, 1972).

For Parsons (1942), married women were "of course" (p. 608) not employed, and those who were did not have jobs which competed for status with those of their husbands, because a woman's role was that of housewife and her status was to be his wife and his children's mother. Moreover, based on Zelditch's (1955) findings, Parsons and Bales (1955) affirmed that family roles were universally divided according to biological sex and, in line with psychoanalytic theory, that a clear division of roles was desirable because of the need for children to achieve identification with the same-sex parent (Michel, 1972). 
The notions of instrumentality and expressiveness proposed by Parsons and Bales (1955) had significant consequences (see Lorenzi-Cioldi, 1994). First, they made it possible to reduce Terman and Miles' (1936) whole set of sentiments, interests, attitudes, and behaviors that measured masculinity and femininity to a small number of stable personality traits. Thus, Parsons and Bales' (1955) dichotomy between instrumentality and expressiveness simplified the research on sex differences.

Furthermore, and as argued by Seward (1946), the different personalities of men and women were not viewed as resulting from their different roles but, instead, justified their separation into two distinct spheres of activity: the public sphere and the private sphere, respectively. Men and women's conformity to their respective roles became an indicator of mental health, and a deviation from their roles an indication of low social adjustment, in turn justifying intervention. This resulted in a growing industry of counseling, marriage guidance and psychotherapy (Connell, 1993).

At that time, research conducted on intersex people by Money and colleagues (Money, Hampson, \& Hampson, 1955) led medical psychologists to go beyond the distinction between males and females and introduce a distinction between sex and gender (see Haig, 2004). According to Muehlenhard and Peterson (2011), these authors defined a gender role as "all those things that a person says or does to disclose himself or herself as having the status of boy or man, girl or woman, respectively" (p. 792). The concept included, among other things, mannerisms, recreational interests, topics of conversation, and the way the person replied to direct inquiries. It supported the point of view presented earlier by anthropologists (Mead, 1935) who attributed the shaping of male and female personalities to culture, rather than biology.

In sum, in the forties and the fifties, male roles and female roles, that is, the roles enacted by white middle-class North Americans, were associated with a set of personality traits which became sufficient to justify their positions in society. The concept of gender role, introduced by medical psychologists, had little influence on the authors who considered men and women as biologically different, and belonging to two exclusive and homogeneous categories. Interestingly, although sex was beginning to be viewed as including more than two categories, gender continued to be conceived as naturally dichotomous.

\section{Time 4. Broadening the Perspectives on Sex Differences}

In Western countries, the 1960 s and 1970 s were marked by an explosion of social movements. In the United States, they brought progress for African Americans, homosexuals, and women: legal segregation of ethnic minorities in public spaces was outlawed in 1964, as was discrimination in the workplace based on race, religion or sex, and homosexuality was removed from the American Psychiatric Association list of mental disorders in 1973 (see Farber \& Bailey, 2001).

There was a massive entry of women into the labor market, and the second wave of feminism rejected all of Parsons and Bales' (1955) conclusions: the complementarity of male and female roles, the impossibility of the same person performing the instrumental and the expressive functions, and spouses' satisfaction with the differentiation of roles (cf. Michel, 1972). Liberal feminists, who were claiming equal rights and opportunities for men and women in all sectors of society, argued that women's emancipation required a change in women's identities and expectations (Friedan, 1963). Indeed, they attributed women's subordinate positions to traditional, stereotyped expectations, disseminated by socializing agents, namely the family, school and the media, and internalized by women. Consequently, they considered it necessary to break down the stereotypes to eliminate gender inequalities (Connell, 1993).

In the 1969 convention of the American Psychological Association, sexist practices were denounced, as was the role of psychological theory in fostering the stereotyping of women (Tiefer, 1991). For many feminist authors, psychologists' conceptions of female nature merely reflected the cultural consensus about what women should be and how they should behave, without considering the influence of social expectations (Weisstein, 1971). In other words, "psychology has looked for inner traits when it should have been looking for social contexts" (Weisstein, 1971, p. 198). The Association for Women in Psychology was then founded, and it stated as one of its goals "to investigate and review psychological research on sex differences in order to establish facts and explode myths" (Tiefer, 1991, p. 638).

Research was undertaken according to three perspectives (Deaux, 1984): 1) sex-role (gender) stereotypes, that is, the beliefs about men and women's specific characteristics, 2) masculine/feminine identity, that is, the psychological construct resulting from the experience of being male or female, and 3) sex differences. 
In brief, research on sex-role stereotypes revealed that people generally believed that men and women were different, that there was a consensus about what these differences were, and that masculine attributes were usually more positively valued than feminine attributes (Broverman, Vogel, Broverman, Clarkson, \& Rosenkrantz, 1972). Broverman and her colleagues (1972) observed two clusters of traits, referring to rationality and instrumentality, and to warmth and expressiveness, respectively, and noted that men were viewed as more instrumental (i.e., independent, competitive, logical, and unemotional) and women as more expressive (i.e., quiet, gentle, caring, and responsive to others). They also found that men and women incorporated the content of their respective sex-role stereotypes into their self-concepts, which led women to have more negative self-concepts than men.

Research on masculine and feminine identities confirmed that men and women's self-descriptions using stereotypical traits were organized into two core dimensions: instrumentality or agency (competence, individualism, orientation towards the task) and expressiveness or communion (friendliness, sensitivity, orientation towards others) (Bem, 1974). However, for Bem (1974), instrumentality and expressiveness were not opposite ends of a single bipolar dimension, as they were for Terman and Miles (1936), but rather they were two separate unidimensional and independent dimensions that made it possible to classify individuals as masculine, feminine or non-sex-typed, that is, androgynous (individuals having high scores of masculinity and femininity) or undifferentiated (individuals having low scores of masculinity and femininity). Bem's Sex-Role Inventory showed that about $50 \%$ of the respondents fell into their respective masculine or feminine categories, $15 \%$ scored higher in the other sex category and 35\% fell into the androgynous category, suggesting that sex-typed individuals were neither the norm nor the condition needed for "good" social adaptation (Bem, 1974).

Regarding research on sex differences, Maccoby and Jacklin (1974) published the results of the first compilation of studies so far carried out by psychologists, analyzing more than 1,400 studies on sex differences in cognitive abilities, temperaments, social behaviors, and memory. They found only four consistent differences which suggested that women had greater verbal ability, men did better in the numerical and visual-spatial domains and were also more aggressive. The other aspects studied led to inconsistent results or demonstrated a lack of differences, contrary to the stereotypes which presented men and women as very different. To explain the origin of sex differences in behaviors, Maccoby and Jacklin (1974) suggested that children were active constructors of their own gender identities through self-socialization: they seek out information about gender, gradually develop a sense of masculinity and femininity and, when they have understood what their own sex is, conform to behaviors socially deemed appropriate to their own sex.

While Maccoby and Jacklin (1974) provided an explanation for the development of sex-typed behaviors, Rubin (1975) proposed an account of the genesis of the belief in sex differences, from the standpoint of anthropology. For this author, all societies divide labor by sex, but differ in the way they separate the tasks between men and women. So, according to Rubin (1975), the division of labor does not stem from biological needs but rather has a purpose: to ensure that an incomplete half finds wholeness in a (heterosexual) marriage. In this perspective, to achieve this goal societies have constructed sex/gender systems which, through the division of labor by sex, separate men and women into two mutually exclusive categories, suppressing their similarities and exacerbating their biological differences, hence creating "gender."

Thus, for many authors, it was essential to distinguish between sex and gender in psychological research. Unger (1979) proposed using gender "to describe those nonphysiological components of sex that are culturally regarded as appropriate to males or to females" (p. 1086). She stressed that differences were studied without considering the situational determinants, or the fact that men and women tended to adopt behaviors in accordance with their stereotypes.

To sum up, authors from the second wave of feminism showed that, contrary to people's beliefs, there were few differences between men and women. They called for a distinction between sex and gender to highlight that the possible differences were a product of society and not of biology. They did not question what was meant by sex and overlooked the fact that the studies on sex-role stereotypes focused on white, middle-class individuals. 


\section{Time 5. From Sex to Gender. Measuring the Effects of Social Contexts}

From the 1980s onwards, the differences between men and women were increasingly referred to as "gender differences" to highlight their social origin (Haig, 2004). The differences between the two social categories were also increasingly assessed by quantitative or meta-analytic techniques that synthesized the research conducted on males and females' cognitive abilities, social behaviors and personality traits (for a summary, see Hyde, 2005).

Meta-analyses that combined the results of studies carried out on cognitive abilities confirmed the results in Maccoby and Jacklin's (1974) work. They showed that females did better than males in verbal tests, whereas males did better than females in the resolution of numerical problems and spatial visualization, namely, the mental rotation of tridimensional figures (Hyde, 1981). However, meta-analyses also indicated that the magnitude of the differences accounted for by gender was small: $1 \%$ of the variance in the verbal and quantitative domains, and $4.5 \%$ in visual-spatial skills.

Meta-analyses were also conducted to summarize the findings of the studies on men and women's social behaviors and personality traits. For instance, data on nonverbal behavior indicated that women were better able than men to decode and encode nonverbal cues (Hall \& Halberstadt, 1981), they were more sensitive to facial expression, corporal language and tone of voice, they smiled more and were more expressive than men. Although gender accounted for less than 4\% of the variance (cf. Deaux, 1984), Hall and Halberstadt (1981) suggested that women's greater ability to encode and decode nonverbal cues was related to their communal role or lower status and stemmed from the self-socialization process described by Maccoby and Jacklin (1974).

A meta-analysis on helping behaviors revealed that, on average, men helped more than women (Eagly \& Crowley, 1986). However, according to Eagly (1987), this finding seemed to come from the fact that helping behaviors were examined in short-term encounters with strangers, or in dangerous situations when onlookers were present, and not in close or long-term relationships where women usually provided more help. The differences in helping behaviors were attributed to gender role expectations, since heroic helping and chivalry are parts of the male role and caring for others part of the female role (Eagly, 1987).

In accordance with the stereotype, data on aggressive behaviors suggested that men and boys engaged in more of certain types of aggressive behaviors than women and girls (Eagly \& Steffen, 1986). The effect of gender accounted for $5 \%$ of the variance (Hyde, 1984) and separate analyses on different types of aggression revealed that differences were most pronounced for physical aggression (Eagly \& Steffen, 1986). Among the explanations proposed, some pointed to women's greater fear of retaliation or greater feelings of guilt in relation to the victim, but also to society's greater tolerance of male aggression than female aggression (Eagly, 1987).

Thus, contrary to authors' expectations, the results of the meta-analyses on social behaviors and personality traits did not show that men and women were mostly similar, but revealed differences stemming from social contexts. This finding stressed the importance of explaining the causes of the differences, rather than merely reporting them.

In effect, the findings of the meta-analyses were associated with the development of various theories. Some suggested that men and women's unequal positions in society affected their interactions (Henley, 1977), and others that adaptive strategies had been developed by males and females throughout history (Buss \& Schmitt, 1993). In her social role theory of sex differences, Eagly (1987) argued that the differences in the traits and behaviors of men and women reflected the stereotypes associated with the social roles traditionally attributed to each sex by a society.

At that time, debates also arose about the relevance of this field of research. For some authors, comparisons between men and women led to a focus on personal rather than social change (Mednick, 1989). For others, the integration of gender comparisons in research designs was likely to highlight women's strengths and abilities, contrary to the comparisons between males and females "inadvertently" made in many studies (Scarr, 1988).

Another more fundamental criticism emerged from the field of sociology, where feminist authors were claiming that not all men and not all women are the same because identities are shaped by specific cultures, social groups, and historical periods (Anthias \& Yuval-Davis, 1983). By excluding other social categorizations from the analyses, the research on sex differences had neglected to show that women were often, but not always, in a dominated position and that, for some people, gender was part of an accumulation of disadvantaged identities (Stacey \& Thorne, 1985; see also 
Shields, 2008). In 1989, the term "intersectionality" was coined by Crenshaw, a feminist lawyer, who defended the need to consider the intersection of gender with other social divisions (see Carastathis, 2014).

In short, meta-analyses conducted in the 1980s revealed the effects of social contexts on men and women's social behaviors and personality traits. These differences were explained by theories that mainly focused on the social positions of men and women, but criticisms about the lack of attention given to the heterogeneity of the gender categories began to surface.

\section{Time 6. Why, Then, Study Sex or Gender Differences?}

Because of its political consequences for the traditional organization of society by sex, research on gender differences became hotly debated in the American academic community in the 1990s. Controversies revolved around the meaning of these differences, the validity of the research findings, the use that might be made of the findings, and the relevance of this field of research (see Eagly, 1995; Hyde \& Plant, 1995; Lott, 1996).

Regarding the meaning of the differences, for authors using meta-analytic techniques, gender differences were small and of relatively little consequence (Deaux, 1984) whereas for authors using qualitative methodologies, they were large and highlighted women's apparent very special caring nature (e.g., Gilligan, 1982). For some authors, gender differences were inconsistent and context-dependent (see Deaux, 1984), whereas for others, variability across studies was the norm in psychological research, and the inconsistencies observed were mainly explained by the contexts in which the studies were conducted (Eagly, 1990). As for the inconsistencies in cognitive abilities, Halpern (1989) claimed that they depended on "what, who, and when (in the life span)" was being tested (p. 1157).

It was also argued that researchers paid more attention to the small number of attributes presenting differences between men and women than to the larger number of attributes that did not show any differences (Lott, 1996). It was still claimed that sex had no predictive value compared to other factors; for example, the literature on sex differences in smiling reported that women smiled more than men, while smiling was considered an indicator of lower status by studies showing that, regardless of gender, applicants for a job smiled more than interviewers (Deutsch, 1990).

With regard to the validity of the research findings, it was claimed that results obtained by meta-analytic techniques might lack accuracy if data came from incorrectly conducted studies (Becker, 1996); possible biases might be due to authors' tendencies to exaggerate or minimize the gender differences according to their preferences (Eagly \& Carli, 1981); earlier research might have created expectations in researchers, leading them to exaggerate rather than minimize the gender differences (Hare-Mustin \& Maracek, 1988); and that, because of a publication bias, studies confirming the existence of sex differences were more likely to be published than studies revealing an absence of difference (Halpern, 1992).

The use that could be made of research findings was especially debated. The usefulness of meta-analyses showing gender differences in cognitive abilities for career guidance was questioned by authors claiming that the variability within the sexes was greater than the variability between the sexes, and that the means were hiding the distribution of the scores (MacIntyre, 1997). Doubts were expressed about the likelihood of improving women's social condition by showing them as different from men on positively valued traits and behaviors, such as caring and expressiveness (Hare-Mustin \& Marececk, 1988). There were concerns that the results of research showing differences might be disseminated by the media, more eager to report gender differences than gender similarities (Hyde \& Plant, 1995), and by conservative social groups, inclined to use the differences to maintain the traditional family organization (Mednick, 1989).

Thus, for some authors, research on sex differences contributed to rationalizing the power differences between the genders and maintaining the barriers preventing progress towards equality (Lott, 1996). For others, this research was perceived as contributing to social change, but this achievement depended on "women's desire to change their status, their political power, and their interest in using psychological research to help them effect change” (Eagly, 1995, p. 155).

With respect to the relevance of this field of research, some authors observed that the studies carried out usually classified all individuals in one of two categories of sex, although sex should not be considered a binary variable (Hird, 2000). They argued that there are many "atypical" combinations of indicators of biological sex (chromosomes, gonads, 
genitalia) even if, in Western culture, surgery and hormones are used, if necessary, to ensure that all fit into only one of two categories (Fausto-Sterling, 2000).

Other authors also claimed that research had been limited to white middle-class American women whose experiences of womanhood were different from those of women in other economic, social, or cultural positions (Shields, 2008). For Prins (2006), "social categories like gender, ethnicity and class co-construct each other ... in myriad ways, dependent on social, historical and symbolic factors" (p. 279), so that assessing, for instance, the effects of being black, working-class, and a woman separately does not accurately reflect the experience of being a black working-class woman (Cole, 2009).

In sum, the research on sex differences drew criticisms in the nineties. Critics pointed to the meaning of the differences, the validity of the results, and the use that might be made of research findings. It was also claimed that the research had failed to question what was meant by sex and to consider the interaction of gender with other social categorizations.

\section{Time 7. So What Now?}

In the 21st century, the world has become globalized. Indices have been developed to measure all kinds of issues and are used to make comparisons within and between countries. Among other statistics, the Gender Inequality Index (GII) has revealed that gender inequalities are the most persistent forms of inequality across countries (UNDP, 2019). Thus, while authors questioned the legitimacy of dividing people into two broad homogeneous categories by revealing the complexity of sex and gender, the data presented by international organizations stressed the fact that women, as a global social category, are still discriminated against worldwide. As a result, while more recent research challenged the gender binary, research using the binary frameworks went on to explore the societal determinants of gender differences and to reveal how normative practices and beliefs about gender continue to maintain inequalities between men and women (see Hyde, Bigler, Joel, Tate, \& van Anders, 2019).

Uncovering societal determinants of sex differences, meta-analyses on cross-cultural variations in gender differences showed, for instance, that differences in mathematics performance existed in some but not all nations (Else-Quest, Hyde, \& Linn, 2010). These findings led researchers to test the impact of various factors on the manifestation of gender differences, namely, to test the impact of economic prosperity, gender equity, family socioeconomic status (Miller \& Halpern, 2013) or stereotype threat (Steele \& Aronson, 1995), that is, the risk that people conform to a negative stereotype.

Meta-analyses also examined changes in the magnitude of gender differences over time. They suggested, for example, that the differences in simple visual reaction times were decreasing, an evolution attributed to the increasing number of women driving and participating in fast-action sports (Silverman, 2006).

In a contrasting perspective, neuroscientists began to study human brains to explore gender differences in cognition, personality traits and behavior: whereas some claim that men and women's brains differ, others argue that human brains cannot be separated into two categories because each brain is a mosaic of male and female elements (Joel, 2011; Joel \& Fausto-Sterling, 2016).

Other meta-analyses examined changes in people's gender identities using data from the Bem Sex-Role Inventory (Donnelly \& Twenge, 2017). Results indicated that, from 1974 to 2012, men's scores on the masculinity and femininity scales had not changed significantly; women's masculinity scores had initially increased but remained stable after 1993, whereas their femininity scores had initially remained stable but declined after 1993. Thus, Donnelly and Twenge (2017) suggested that the psychological traits included in the BSRI might no longer capture people's conceptions of masculinity and femininity.

Gender identities were analyzed from another, multifactorial, perspective on gender identity, according to which masculinity and femininity are not organized by instrumentality and expressiveness, but include loosely related components, such as physical attributes, abilities, interests, preferences, and personality traits (Spence, 1993). For instance, a study conducted with participants of various ethnicities showed that gender-typed hobbies better predicted the judgment of being "masculine" or "feminine" than personality traits like being assertive and independent or compassionate 
and understanding (Lippa, 2005). Results suggested that men were more interested in activities like fishing, playing poker or weightlifting, and women more interested in activities like aerobics, clothes shopping, or watching romantic movies (Lippa, 2005; see also McGinnis, Chun, \& McQuillan, 2003).

Research was also conducted on professional interests and preferences. A meta-analysis on job attribute preferences revealed that women declared a preference for jobs with good hours, easy commuting, and the opportunity to help others, and men a preference for jobs in which they could work alone, and which provided leisure time off the job (Konrad, Ritchie, Lieb, \& Corrigall, 2000). The main finding of a meta-analysis on vocational interests suggested that men were interested in things and women in people (Su, Rounds, \& Armstrong, 2009).

Research on men and women's professional interests and preferences highlighted that conformity to sex-typed ways of thinking and normative behaviors functions to maintain gender inequalities: people's interests and preferences reflect the segregation by sex at the workplace and contribute to its maintenance. Indeed, it was shown that men are still over-represented in high-status positions and jobs related to engineering, sciences and mathematics, and women over-represented in low-status positions and socially-oriented jobs such as nursing, social work, or kindergarten teaching (Charles \& Bradley, 2009; International Labour Organization [ILO], 2018).

Similarly, research conducted in the private sphere revealed that the prevalence of traditional family organization leads women to defend the female caregiver role and its associated tasks (Poeschl, Ribeiro, \& Oliveira, 2018) and, like men, to hold negative attitudes towards marriages in which the man stays at home and the woman is the breadwinner (Brescoll \& Uhlmann, 2005; Rochlen, McKelley, \& Whittaker, 2010). As a result, in developed countries, women's ways of thinking contribute to maintaining the gender inequalities linked to the traditional division of labor in the family (Ferrant, Pesando, \& Nowacka, 2014; World Economic Forum [WEF], 2018).

Finally, authors who analyzed the impact of socializing agents, for example, the family, school and the media, on the shaping of people's ways of thinking highlighted the contribution of these agents to the slowing down of the move towards gender equality. These authors stressed that news media continue to give more space to male personalities, men's comments, or masculine sports (Crawford \& Unger, 2000; for online news media see Jia, Lansdall-Welfare, Sudhahar, Carter, \& Cristianini, 2016); they showed that recent films and television drama programs less often present female scientists in lower-status positions, but emphasize their glamour and attractiveness, directing attention to their looks rather than their professional skills (Steinke, 2013); they revealed that the literature for small children still tends to depict male characters in the central role, and female characters in domestic roles (Dafflon-Novelle, 2002; Filipović, 2018) and that the works studied in high school literature classes often portray traditional male and female characters (Poeschl, Silva, \& Clémence, 2004).

In summary, research conducted in the 21st century has confirmed the variability of gender differences across time and cultures and revealed how the conceptions of gender are anchored in social organization and contribute to its reproduction. Even if researchers no longer consider sex and gender as dichotomous and homogeneous categories, the sex/gender binary still molds people's ways of thinking and behaving and continues to support discrimination against women in societies of Western culture and beyond.

\section{Concluding Observations}

This paper briefly reviewed a hundred years of research on sex differences, a field of research which cannot be separated from women's struggles for gender equality. It recalled how, at the beginning of the 20th century, North American female psychologists initiated a systematic analysis of the studies conducted by male authors on the differences between the sexes, studies that contributed to justifying the fact that women had lower status and less power in society. At that time, women were just beginning to acquire some rights, namely the right to vote, to own property and to access education and, since then, the field of research on sex differences has accompanied women's struggle for equality with men, which had both scientific and political implications.

Initially, research on sex differences consisted of the simple comparison of a variety of traits that might differentiate males and females. It then shifted to the selection of those traits that could more precisely define "masculinity" and "femininity," which were also those more likely to justify the roles traditionally performed by white middle-class men 
and women from countries of Western culture. In the sixties and the seventies, driven by the second wave of feminism, female authors adopted research strategies that aimed to improve the research on sex differences. They revealed how society, more than biology, shaped men and women's personalities and behaviors and developed theories to explain the causes of the differences found in studies on sex differences. In this sense, as Eagly (1995) stated, this field of research encountered "a powerful political agenda" (p. 155) in the struggle for a fairer society.

Feminist movements succeeded in obtaining the same political rights for women as for men, and scientific research unveiled the small number of stable sex differences, but their efforts failed to achieve equality between the sexes. Today there are still large differences in the way social roles are distributed between men and women and between men and women's social statuses; many people still believe that men and women are different kinds of persons and still develop a gender identity consistent with traditional cultural norms.

These observations are supported by the conclusion of the United Nations Development Programme Report (UNDP, 2019), which suggests that women's progress towards equality is slowed by persistent social norms that prescribe social roles and power relations between men and women. As a result, the gender gap remains the widest in the highest layers of power and responsibility. In politics, in 2019 only $24 \%$ of the world's national parliamentarians were women, usually with responsibilities in the environmental and social sectors, and only $10 \%$ of heads of state and government were women (UNDP, 2019). In the economic sector, in 2020, women occupied $21.2 \%$ of board seats and held $5.8 \%$ of CEO positions of the largest North American companies listed in the Standard and Poor's 500 index (Catalyst, 2020).

Not only do women gain little access to the top positions in companies but they also remain concentrated in some sectors of the labor market, where generally they continue to be paid less than men (Hegewisch \& Barsi, 2019). In the family, they still carry out most of the unpaid family work (UNDP, 2019) because, as research suggests, women think about domestic work as a feminine activity and, in developed countries, consider the private sphere their sphere of power (Allen \& Hawkins, 1999). Thus, it seems that a change in men and women's social roles and power relations might constitute a threat to people's gender identities which hinders social change (for a discussion about the psychological aspects of social change, see De la Sablonnière, 2017).

These conclusions do not imply that women's efforts to undertake research from the perspective of social change have been worthless. By showing the absence of a scientific basis for the claim that most apparent sex differences have a biological basis, and by highlighting the impact of social roles on men and women's beliefs and behaviors, research on sex differences has contributed to helping those who challenge social norms to strive for more equality.

However, the uneven pace of progress towards gender equality indicates that research is still needed to achieve social change, and suggests that it should focus on the beliefs and behaviors that maintain segregation by sex in both the public and the private spheres. Research should also go beyond the focus on the differences between males and females. Because sex is not a dichotomous variable and the gender categories are not distinct and homogeneous social categories, more complex studies challenging the sex/gender binary system need to be carried out if a more inclusive world is to be promoted.

Finally, it should be borne in mind that even though scientific research often addresses important problems faced by societies, its findings are insufficient to produce social change in the absence of social awareness and political willingness. Nonetheless, a hundred years of research on sex differences highlights that scientific research can produce arguments that may be used to promote social change, and that seeking to question the justifications for social inequalities may be an effective way to achieve a fairer society.

Funding: The author has no funding to report.

Acknowledgments: The author thanks the anonymous reviewers who provided valuable suggestions and comments on earlier drafts of the manuscript.

Competing Interests: The author has declared that no competing interests exist. 


\section{References}

Allen, S. M., \& Hawkins, A. J. (1999). Maternal gatekeeping: Mothers' beliefs and behaviors that inhibit greater father involvement in family work. fournal of Marriage and the Family, 61, 199-212. https://doi.org/10.2307/353894

Anthias, F., \& Yuval-Davis, N. (1983). Contextualizing feminism: Gender, ethnic and class divisions. Feminist Review, 15, $62-75$. https://doi.org/10.1057/fr.1983.33

Bales, R. F. (1950). Interaction process analysis: A method for the study of small groups. Chicago, IL, USA: University of Chicago Press.

Becker, G. (1996). Bias in the assessment of gender differences. American Psychologist, 51, 154-155. https://doi.org/10.1037/0003-066X.51.2.154

Bem, S. L. (1974). The measurement of psychological androgyny. Journal of Clinical and Consulting Psychology, 42, 155-162. https://doi.org/10.1037/h0036215

Berger, P. L., \& Luckmann, T. (1966). The social construction of reality. New York, NY, USA: Penguin Books.

Brescoll, V. L., \& Uhlmann, E. L. (2005). Attitudes toward traditional and nontraditional parents. Psychology of Women Quarterly, 29, 436-445. https://doi.org/10.1111/j.1471-6402.2005.00244.x

Broverman, I. K., Vogel, S. R., Broverman, D. M., Clarkson, F. E., \& Rosenkrantz, P. S. (1972). Sex-role stereotypes: A current appraisal. fournal of Social Issues, 28, 59-78. https://doi.org/10.1111/j.1540-4560.1972.tb00018.x

Buss, D. M., \& Schmitt, D. P. (1993). Sexual strategies theory: An evolutionary perspective on human mating. Psychological Review, 100, 204-232. https://doi.org/10.1037/0033-295X.100.2.204

Carastathis, A. (2014). The concept of intersectionality in feminist theory. Philosophy Compass, 9, 304-314. https://doi.org/10.1111/phc3.12129

Catalyst. (2020, January). Pyramid: Women in S\&P 500 companies. Retrieved from Catalyst Website: https:/www.catalyst.org/research/women-in-sp-500-companies/

Charles, M., \& Bradley, K. (2009). Indulging our gendered selves? Sex segregation by field of study in 44 countries. American fournal of Sociology, 114, 924-976. https://doi.org/10.1086/595942

Charmaz, K. (2006). Constructing grounded theory. London, United Kingdom: SAGE.

Cole, E. R. (2009). Intersectionality and research in psychology. American Psychologist, 64, 170-180. https://doi.org/10.1037/a0014564

Connell, R. W. (1993). Gender and power. Society, the person and sexual politics. Cambridge, United Kingdom: Polity Press.

Constantinople, A. (1973). Masculinity-femininity: An exception to a famous dictum? Psychological Bulletin, 80, 389-407. https://doi.org/10.1037/h0035334

Crawford, M., \& Unger, R. K. (2000). Women and gender: A feminist psychology. New York, NY, USA: McGraw-Hill.

Dafflon-Novelle, A. (2002). Les représentations multidimensionnelles du masculin et du féminin véhiculées par la presse enfantine francophone. Swiss fournal of Psychology, 61, 85-103. https://doi.org/10.1024//1421-0185.61.2.85

Deaux, K. (1984). From individual differences to social categories: Analysis of a decade's research on gender. American Psychologist, 39, 105-116. https://doi.org/10.1037/0003-066X.39.2.105

De la Sablonnière, R. (2017). Toward a psychology of social change: A typology of social change. Frontiers in Psychology, 8, Article 397. https://doi.org/10.3389/fpsyg.2017.00397

Deutsch, F. M. (1990). Status, sex, and smiling: The effect of role on smiling in men and women. Personality and Social Psychology Bulletin, 16, 531-540. https://doi.org/10.1177/0146167290163011

Donnelly, K., \& Twenge, J. M. (2017). Masculine and feminine traits on the Bem Sex-Role Inventory, 1993-2012: A cross-temporal meta-analysis. Sex Roles, 76, 556-565. https://doi.org/10.1007/s11199-016-0625-y

Eagly, A. H. (1987). Sex differences in social behavior: A social-role interpretation. Hillsdale, NJ, USA: Erlbaum.

Eagly, A. H. (1990). On the advantages of reporting sex comparisons. American Psychologist, 45, 560-562. https://doi.org/10.1037/0003-066X.45.4.560

Eagly, A. H. (1995). The science of politics of comparing women and men. American Psychologist, 50, 145-158. https://doi.org/10.1037/0003-066X.50.3.145

Eagly, A. H., \& Carli, L. L. (1981). Sex of researchers and sex-typed communications as determinants of sex differences in influenciability: A meta-analysis of social influence studies. Psychological Bulletin, 90, 1-20.

https://doi.org/10.1037/0033-2909.90.1.1 
Eagly, A. H., \& Crowley, M. (1986). Gender and helping behavior: A meta-analytic review of the social psychological literature. Psychological Bulletin, 100, 283-308. https://doi.org/10.1037/0033-2909.100.3.283

Eagly, A. H., \& Steffen, V. J. (1986). Gender and aggressive behavior: A meta-analytic review of the social psychological literature. Psychological Bulletin, 100, 309-330. https://doi.org/10.1037/0033-2909.100.3.309

Else-Quest, N. M., Hyde, J. S., \& Linn, M. C. (2010). Cross-national patterns of gender differences in mathematics: A meta-analysis. Psychological Bulletin, 136, 103-127. https://doi.org/10.1037/a0018053

Farber, D., \& Bailey, B. (2001). The Columbia guide to America in the 1960s. New York, NY, USA: Columbia University Press.

Fausto-Sterling, A. (2000). The sex/gender perplex. Studies in History and Philosophy of Science Part C: Studies in History and Philosophy of Biological and Biomedical Sciences, 31, 637-646. https://doi.org/10.1016/S1369-8486(00)00003-0

Ferrant, G., Pesando, L. M., \& Nowacka, K. (2014). Unpaid care work: The missing link in the analysis of gender gaps in labour outcome. Retrieved from OECD Development Center Website: http://www.oecd.org/dev/development-gender/Unpaid_care_work.pdf

Filipović, K. (2018). Gender representation in children's books: Case of an early childhood setting. Fournal of Research in Childhood Education, 32, 310-325. https://doi.org/10.1080/02568543.2018.1464086

Friedan, B. (1963). The feminine mystique. New York, NY, USA: Norton.

Furumoto, L., \& Scarborough, E. (1986). Placing women in the history of psychology: The first American women psychologists. American Psychologist, 41, 35-42. https://doi.org/10.1037/0003-066X.41.1.35

Gilligan, C. (1982). In a different voice: Psychological theory and women's development. Cambridge, MA, USA: Harvard University Press. Gould, S. J. (1981). The mismeasure of man. New York, NY, USA: Norton.

Ha, N. Q. (2011). The riddle of sex: Biological theories of sexual difference in the early twentieth-century. Fournal of the History of Biology, 44, 505-546. https://doi.org/10.1007/s10739-010-9257-1

Haig, D. (2004). The inexorable rise of gender and the decline of sex: Social change in academic titles, 1945-2001. Archives of Sexual Behavior, 33, 87-96. https://doi.org/10.1023/B:ASEB.0000014323.56281.0d

Hall, J. A., \& Halberstadt, A. G. (1981). Sex roles and nonverbal communication skills. Sex Roles, 7, 273-287. https://doi.org/10.1007/BF00287542

Halpern, D. F. (1989). The disappearance of cognitive gender differences: What you see depends on where you look. American Psychologist, 44, 1156-1158. https://doi.org/10.1037/0003-066X.44.8.1156

Halpern, D. F. (1992). Sex differences in cognitive abilities. Hillsdale, NJ, USA: Erlbaum.

Hare-Mustin, R. T., \& Marecek, J. (1988). The meaning of difference: Gender theory, postmodernism, and psychology. American Psychologist, 43, 455-464. https://doi.org/10.1037/0003-066X.43.6.455

Hegewisch, A., \& Barsi, Z. (2019). Fact sheet: The gender wage gap by occupation 2018 and by race and ethnicity. Retrieved from the Institute for Women's Policy Research Website: https://iwpr.org/wp-content/uploads/2020/07/2020-Occupational-wage-gap-FINAL.pdf

Henley, N. M. (1977). Body politics: Power, sex and non-verbal communication. Englewood Cliffs, NJ, USA: Prentice-Hall.

Hird, M. J. (2000). Gender's nature: Intersexuality, transsexualism and the "sex"/"gender” binary. Feminist Theory, 1, 347-364. https://doi.org/10.1177/146470010000100305

Hollingworth, S. (1916a). The vocational aptitudes of women. In H. L. Hollingworth (Ed.), Vocational psychology: Its problems and method (pp. 222-244). New York, NY, USA: D’Appleton \& Company.

Hollingworth, S. (1916b). Social devices for impelling women to bear and rear children. American fournal of Sociology, 22, $19-19$. https://doi.org/10.1086/212572

Hyde, J. S. (1981). How large are cognitive gender differences? A meta-analysis using $\omega 2$ and d. American Psychologist, 36, 892-901. https://doi.org/10.1037/0003-066X.36.8.892

Hyde, J. S. (1984). How large are gender differences in aggression? A developmental meta-analysis. Developmental Psychology, 20, 722-736. https://doi.org/10.1037/0012-1649.20.4.722

Hyde, J. S. (2005). The gender similarities hypothesis. American Psychologist, 60, 581-592. https://doi.org/10.1037/0003-066X.60.6.581

Hyde, J. S., Bigler, R. S., Joel, D., Tate, C. C., \& van Anders, S. M. (2019). The future of sex and gender in psychology: Five challenges to the gender binary. American Psychologist, 74, 171-193. https://doi.org/10.1037/amp0000307

Hyde, J. S., \& Plant, E. A. (1995). Magnitude of psychological gender differences: Another side to the story. American Psychologist, 50, 169-171. https://doi.org/10.1037/0003-066X.50.3.159 
International Labour Organization. (2018). World employment social outlook: Trends for women 2018. Retrieved from ILO Website: https:/www.ilo.org/wcmsp5/groups/public/---dgreports/---dcomm/---publ/documents/publication/wcms_615594.pdf

Jia, S., Lansdall-Welfare, T., Sudhahar, S., Carter, C., \& Cristianini, N. (2016). Women are seen more than heard in online newspapers. PLoS One, 11, Article e0148434. https://doi.org/10.1371/journal.pone.0148434

Joel, D. (2011). Male or female? Brains are intersex. Frontiers in Integrative Neuroscience, 5, Article 57. https://doi.org/10.3389/fnint.2011.00057

Joel, D., \& Fausto-Sterling, A. (2016). Beyond sex differences: New approaches for thinking about variation in brain structure and function. Philosophical Transactions of the Royal Society B, 371, Article 20150461. https://doi.org/10.1098/rstb.2015.0451

Konrad, A. M., Ritchie, J. E., Jr., Lieb, P., \& Corrigall, E. (2000). Sex differences and similarities in job attribute preferences: A metaanalysis. Psychological Bulletin, 126, 593-641. https://doi.org/10.1037/0033-2909.126.4.593

Lee, P. C. (1976). Psychology and sex differences. In P. C. Lee \& R. S. Stewart (Eds.), Sex differences: Cultural and developmental dimensions (pp. 359-370). New York, NY, USA: Urizen Books.

Lippa, R. A. (2005). How do lay people weight information about instrumentality, expressiveness, and gender-typed hobbies when judging masculinity-femininity in themselves, best friends, and strangers? Sex Roles, 53, 43-55.

https://doi.org/10.1007/s11199-005-4277-6

Lorenzi-Cioldi, F. (1994). Les androgynes. Paris, France: Presses Universitaires de France.

Lott, B. (1996). Politics or science? The question of gender sameness/difference. American Psychologist, 51, 155-157. https://doi.org/10.1037/0003-066X.51.2.155

Maccoby, E. E., \& Jacklin, C. N. (1974). The psychology of sex differences. Stanford, CA, USA: Stanford University Press.

MacIntyre, T. (1997). Gender differences in cognition: A minefield of research issues. Irish fournal of Psychology, 18, 386-396. https://doi.org/10.1080/03033910.1997.1010558158

McGinnis, L., Chun, S., \& McQuillan, J. (2003). A review of gendered consumption in sport and leisure. Academy of Marketing Science Review, 5, 1-24. http://www.amsreview.org/articles/mcginnis05-2003.pdf

Mead, M. (1935). Sex and temperament in three primitive societies. Oxford, United Kingdom: William Morrow.

Mednick, M. T. (1989). On the politics of psychological constructs: Stop the bandwagon, I want to get off. American Psychologist, 44, 1118-1123. https://doi.org/10.1037/0003-066X.44.8.1118

Michel, A. (1972). Sociologie de la famille et du mariage. Paris, France: Presses Universitaires de France.

Miller, D. I., \& Halpern, D. F. (2013). The new science of cognitive sex differences. Trends in Cognitive Sciences, 18, 37-45. https://doi.org/10.1016/j.tics.2013.10.011

Money, J., Hampson, J. G., \& Hampson, J. L. (1955). An examination of some basic sexual concepts: The evidence of human hermaphroditism. Johns Hopkins Hospital Bulletin, 97, 301-319.

Muehlenhard, C. L., \& Peterson, A. D. (2011). Distinguishing between sex and gender: History, current conceptualizations, and implications. Sex Roles, 64, 791-803. https://doi.org/10.1007/s11199-011-9932-5

Nielsen, J. M. (1990). Sex and gender in society: Perspectives on stratification. Prospect Heights, IL, USA: Waveland Press.

Parsons, T. (1942). Age and sex in the social structure of the United States. American Sociological Review, 7, 604-616. https://doi.org/10.2307/2085686

Parsons, T., \& Bales, R. F. (1955). Family: Socialization, and interaction process. Glencoe, IL, USA: Free Press.

Poeschl, G., Ribeiro, R., \& Oliveira, N. (2018). Organizing principles, habitus and family practices. Cadernos de Pesquisa, 48, 70-98. https://doi.org/10.1590/1980531434280

Poeschl, G., Silva, A., \& Clémence, A. (2004). Representações da masculinidade e da feminilidade e retratos de homens e mulheres na literatura portuguesa. Psicologia, 18, 31-46. https://doi.org/10.17575/rpsicol.v18i1.410

Prins, B. (2006). Narrative accounts of origins: A blind spot in the intersectional approach? European fournal of Women's Studies, 13, 277-290. https://doi.org/10.1177/1350506806065757

Rochlen, A. B., McKelley, R. A., \& Whittaker, T. A. (2010). Stay-at-home fathers' reasons for entering the role and stigma experiences: A preliminary report. Psychology of Men \& Masculinity, 11, 279-285. https://doi.org/10.1037/a0017774

Rubin, G. (1975). The traffic in women: Notes on the "political economy" of sex. In R. R. Reiter (Ed.), Toward an anthropology of women (pp. 157-210). New York, NY, USA: Monthly Review Press.

Scarr, S. (1988). Race and gender as psychological variables: Social and ethical issues. American Psychologist, $43,56-59$. https://doi.org/10.1037/0003-066X.43.1.56 
Scott, J. W. (1995). The woman worker. In G. Fraisse, G. Duby, \& M. Perrot (Eds.), History of women in the west (Vol. 4, pp. 399-426). Cambridge, MA, USA: Belknap Press.

Seward, G. H. (1946). Sex and the social order. New York, NY, USA: McGraw-Hill.

Shields, S. A. (1975). Funcionalism, Darwinism, and the psychology of women: A study in social myth. American Psychologist, 30, 739-754. https://doi.org/10.1037/h0076948

Shields, S. A. (2008). Gender: An intersectionality perspective. Sex Roles, 59, 301-311. https://doi.org/10.1007/s11199-008-9501-8

Silverman, I. W. (2006). Sex differences in simple visual reaction time: A historical meta-analysis. Sex Roles, 54, 57-68. https://doi.org/10.1007/s11199-006-8869-6

Spence, J. T. (1993). Gender-related traits and gender ideology: Evidence for a multifactorial theory. Fournal of Personality and Social Psychology, 64, 624-635. https://doi.org/10.1037/0022-3514.64.4.624

Stacey, J., \& Thorne, B. (1985). The missing feminist revolution in sociology. Social Problems, 32, 301-316. https://doi.org/10.2307/800754

Steele, C. M., \& Aronson, J. (1995). Stereotype threat and the intellectual test performance of African Americans. fournal of Personality and Social Psychology, 69, 797-811. https://doi.org/10.1037/0022-3514.69.5.797

Steinke, J. (2013). Portrayals of women scientists in the mass media. In A. N. Valdivia \& S. R. Mazzarella (Eds.), The international encyclopedia of media studies (Vol. 3, pp. 1-18). Oxford, United Kingdom: Blackwell.

Strong, E. K. (1936). Interest of men and women. Journal of Social Psychology, 7, 49-67. https://doi.org/10.1080/00224545.1936.9921647

Strong, E. K. (1955). Vocational interests 18 years after college. Minneapolis, MN, USA: University of Minnesota Press.

Su, R., Rounds, J., \& Armstrong, P. I. (2009). Men and things, women and people: A meta-analysis of sex differences in interests. Psychological Bulletin, 135, 859-884. https://doi.org/10.1037/a0017364

Terman, L. M., \& Miles C. C. (1936). Sex and personality: Studies in masculinity and femininity. New York, NY, USA: McGraw-Hill.

Thorndike, E. L. (1914). Educational psychology (Vol. 3). New York, NY, USA: Teacher's College, Columbia University.

Tiefer, L. (1991). A brief history of the association for women in psychology 1969-1991. Psychology of Women Quarterly, 15, 635-649. https://doi.org/10.1111/j.1471-6402.1991.tb00436.x

Unger, R. K. (1979). Toward a redefinition of sex and gender. American Psychologist, 34, 1085-1094. https://doi.org/10.1037/0003-066X.34.11.1085

United Nations Development Programme (UNDP). (2019). Human development report 2019. Retrieved from the UNDP Website: http://hdr.undp.org/sites/default/files/hdr2019.pdf

Weisstein, N. (1971). Psychology constructs the female. Fournal of Social Education, 35, 362-373.

Woolley, H. T. (1910). A review of the recent literature on the psychology of sex. Psychological Literature, 7, 335-342. https://doi.org/10.1037/h0066338

Woolley, H. T. (1914). The psychology of sex. Psychological Bulletin, 11, 353-379. https://doi.org/10.1037/h0070064

World Economic Forum. (2018). The global gender gap report 2018. Retrieved from the WEF Website: http://www3.weforum.org/docs/WEF_GGGR_2018.pdf

Zelditch, M., Jr. (1955). Role determination in nuclear family. In T. Parsons \& R. F. Bales (Eds.), Family: Socialization, and interaction process (pp. 307-352). Glencoe, IL, USA: Free Press. 